REVIEW

\title{
Is impairment of ischaemic preconditioning by sulfonylurea drugs clinically important?
}

\author{
J J Meier, B Gallwitz, W E Schmidt, A Mügge, M A Nauck
}

Heart 2004;90:9-12

In the UGDP study, published in the 1970s, a high incidence of cardiovascular mortality was found in patients treated with the sulfonylurea agent tolbutamide. Impaired ischaemic preconditioning is presumed to be the most important mechanism for the excess cardiovascular mortality observed. However, as tolbutamide has only a low affinity for cardiac sulfonylurea receptors, interference with ischaemic preconditioning seems unlikely to account for this excess mortality. Several smaller studies also failed to establish a definite link between sulfonylurea treatment before acute myocardial infarction and in-hospital mortality. However, when the myocardium becomes exposed to repeated or prolonged periods of ischaemia, ischaemic preconditioning may become clinically important. Myocardial ischaemia can also develop during emergency or elective angioplasty and during coronary bypass surgery. Therefore discontinuation of sulfonylurea treatment should be considered in these circumstances.

See end of article for authors' affiliations

Correspondence to: Prof Dr Med Michael A Nauck, Diabeteszentrum Bad Lauterberg, Kirchberg 21, Bad Lauterberg im Harz, D-37431, Germany; m.nauck@

diabeteszentrum.de

Accepted 17 June 2003
O wing to their potent antidiabetic properties, sulfonylureas have become the leading oral antihyperglycaemic agents over the past half century. ${ }^{1}$ The ongoing discussion about potentially detrimental side effects produced by sulfonylureas started in the 1970s with the publication of the university group diabetes program (UGDP) study. This study showed an increase in cardiovascular mortality in type 2 diabetic patients taking tolbutamide, a first generation sulfonylurea. ${ }^{2}$ For a long time, no mechanism was proposed to explain the detrimental effects of tolbutamide. The discovery of sulfonylurea receptors (SUR) on vascular cells (SUR 2B) and on cardiomyocytes (SUR 2A) triggered the discussion about impairment of ischaemic preconditioning as the most probable mechanism underlying the increased mortality observed. $^{3-6}$ Today, sulfonylureas are still the most frequently prescribed drugs for the treatment of type 2 diabetes mellitus. ${ }^{7}$ However, opinions on their potentially detrimental effects continue to diverge. ${ }^{8} 9$

\section{TISSUE SPECIFIC SUR AFFINITIES OF SULFONYLUREAS AND RELATED \\ SUBSTANCES}

When evaluating studies on the effects of sulfonylureas in relation to ischaemic preconditioning, it is important to assess the various sulfonylurea agents individually, as they differ with respect to their selectivity for SUR receptor subtypes. Tolbutamide-the oldest member of the sulfonylurea family — has a high affinity for B cell SUR I receptors, but only a very low affinity for SUR 2A receptors expressed on cardiomyocytes $^{10-12}$ (table 1). In contrast, glibenclamide inhibits cardiac SUR 2A as well as pancreatic SUR 1 with high affinity. ${ }^{11}$ Gliclazide, a second generation sulfonylurea, is characterised by a higher selectivity for pancreatic $\mathrm{K}_{\mathrm{ATP}}$ channels. ${ }^{13}$ As with glibenclamide, glimepiride-the most novel sulfonylurea-does not differentiate between B cells, cardiac muscle, or smooth muscle $\mathrm{K}_{\mathrm{ATP}}$ channels. ${ }^{14}$ The benzoic acid derivatives meglitinide and repaglinide also target SUR 1 and SUR 2A receptors potently, ${ }^{11}{ }^{15}$ whereas nateglinde shows a higher selectivity for SUR 1 receptors $^{16}$ (table 1).

\section{EXPERIMENTAL EVIDENCE FOR IMPAIRMENT OF ISCHAEMIC PRECONDITIONING BY SULFONLYUREAS Insights from animal models}

Evidence produced from various animal studies supports the hypothesis that ischaemic preconditioning is impaired by sulfonylureas. Gross and Auchampach studied the effects of glibenclamide in dogs. ${ }^{3}$ The animals were subjected to a 60 minute occlusion of the left circumflex coronary artery, followed by five hours of reperfusion. Ischaemic preconditioning (that is, repetitive, short lasting occlusions of the coronary artery before a prolonged occlusion) led to a significant reduction in myocardial necrosis; however, this effect was completely abolished by glibenclamide. ${ }^{3}$ In agreement with this, Toombs et al found that co-administration of glibenclamide reversed the cardioprotective effect of ischaemic preconditioning in rabbits. ${ }^{4}$ Using perfused rat hearts, Mocanu et al showed that glibenclamide, but not glimepiride, abolished ischaemic preconditioning. ${ }^{17}$

\section{Controlled myocardial ischaemia in humans}

As studies involving the induction of repeated ischaemic episodes in humans are simply not feasible, evidence can only be derived indirectly. Cleveland et al studied ischaemic preconditioning in isolated human atrial muscle trabeculae

Abbreviations: DIGAMI, diabetes mellitus, insulin glucose infusion in acute myocardial infarction; SUR, sulfonylurea receptor; UGDP, university group diabetes program; UKPDS, UK prospective diabetes study 
Table 1 Different affinities of sulfonylurea and benzoic acid derivates for SUR subtypes

\begin{tabular}{|c|c|c|c|c|}
\hline Generic name & $\begin{array}{l}\text { SUR } 1 \text { (pancreatic B } \\
\text { cells) } K_{i}^{*} \text { [Lnit] }\end{array}$ & $\begin{array}{l}\text { SUR 2A } \\
\text { (cardiomyocytes) } \\
\mathrm{K}_{\mathrm{i}}^{*} \text { [unit] }\end{array}$ & $\begin{array}{l}\text { Relative affinity } \\
\text { SUR 1/SUR 2A }\end{array}$ & Reference \\
\hline $\begin{array}{l}\text { Tolbutamide } \\
\text { Glibenclamide } \\
\text { Gliclazide } \\
\text { Glimepiride } \\
\text { Meglitinide } \\
\text { Repaglinide } \\
\text { Nateglinide }\end{array}$ & $\begin{array}{l}5.4(3.4) \mu \mathrm{mol} / \mathrm{I} \\
4.2 \mathrm{nmol} / \mathrm{l} \\
50(7) \mathrm{nmol} / \mathrm{I} \\
5.4(0.1) \mathrm{nmol} / \mathrm{I} \\
0.26(0.06) \mu \mathrm{mol} / \mathrm{I} \\
7.4(1.2) \mathrm{nmol} / \mathrm{l} \\
7.4(0.2) \mu \mathrm{mol} / \mathrm{l}\end{array}$ & $\begin{array}{l}1.7(0.2) \mathrm{mmol} / \mathrm{I} \\
27(2) \mathrm{nmol} / \mathrm{I} \\
0.8(0.1) \mathrm{mmol} / \mathrm{I} \\
7.3(0.23) \mathrm{nmol} / \mathrm{I} \\
0.53(0.11) \mu \mathrm{mol} / \mathrm{I} \\
8.7(1.5) \mathrm{nmol} / \mathrm{I} \\
2.3(1.2) \mathrm{mmol} / \mathrm{l}\end{array}$ & $\begin{array}{l}314.8 \\
6.4 \\
16000 \\
1.35 \\
2.0 \\
1.2 \\
311\end{array}$ & $\begin{array}{l}11,12 \\
11 \\
13 \\
14 \\
11 \\
15 \\
16\end{array}$ \\
\hline \multicolumn{5}{|c|}{$\begin{array}{l}\text { Values are mean (SD). } \\
{ }^{*} \text { Concentration of half maximal inhibition. } \\
\text { SUR, sulfonylurea receptor. }\end{array}$} \\
\hline
\end{tabular}

obtained from type 2 diabetic patients treated with or without sulfonylureas before coronary artery surgery. ${ }^{18}$ The trabeculae were subjected to 45 minutes of ischaemia followed by 120 minutes of reperfusion. Ischaemic preconditioning was simulated by prior induction of ischaemia for five minutes. The muscular contractile force, a marker of myocardial integrity, was increased by ischaemic preconditioning; however, this protective effect was absent in the patients receiving sulfonylureas. ${ }^{18}$

Changes in left ventricular ejection fraction and end diastolic volume-indicators of ischaemic myocardial dysfunction-were recently assessed by echocardiography during dipyridamole administration in a study by Scognamiglio et al. ${ }^{19}$ These investigators found a significant reduction in both variables during glibenclamide administration but not during insulin treatment, indicating a reduction in ischaemic preconditioning by the sulfonylurea drug.

Tomai and colleagues recorded ST segment shifts on an intracoronary ECG and applied them as an index of myocardial alterations during two subsequent episodes of intracoronary balloon inflation in 20 patients pretreated with either glibenclamide or placebo. ${ }^{5}$ The investigators found that the ST shifts were reduced during the second balloon inflation in the placebo treated patients, whereas the ST segment remained unchanged during the first and second inflation in patients pretreated with glibenclamide. ${ }^{5}$ Similarly, Lee at al found that glibenclamide increased the ST segment deviations after the administration of the $\mathrm{K}^{+}$ channel opener nicorandil. ${ }^{20}$ Klepzig et al compared the effects of glibenclamide, glimepiride, and placebo administration on ST segment shifts. ${ }^{21}$ Glibenclamide prevented ischaemic preconditioning, while it was largely maintained after glimepiride administration. These data are strongly supported by a recent study by Lee and Chou, which showed that shifts of the ST segment were increased by pretreatment with glibenclamide in patients with and without type 2 diabetes. $^{22}$ In contrast, pretreatment with glimepiride only marginally affected cardioprotection arising from ischaemic preconditioning. ${ }^{22}$

A word of caution is necessary regarding the interpretation of studies using ST segment deviations as an indicator of myocardial ischaemia, as a large part of the ST segment change is mediated by sarcolemmal $\mathrm{K}_{\mathrm{ATP}}$ channels. ${ }^{23}$ It is possible that sulfonylureas block these channels as well, thereby perturbing ST segment changes recorded on the ECG. This may limit the interpretation of studies using ST segment changes as a surrogate for the cardiac effects of compounds with a modulating activity at $\mathrm{K}_{\mathrm{ATP}}$ channels, such as the sulfonylureas.

The different effects of glimepiride and glibenclamide on ischaemic preconditioning ${ }^{17} 2122$ are surprising, as the relative affinity to cardiac SUR 2A receptors compared with pancreatic SUR 1 receptors has been shown to be comparable for both compounds when studied in excised patches. ${ }^{14}$ However, in isolated ventricular myocytes, the half maximal inhibitory concentration of glimepiride has been reported to be $31.6 \mathrm{nM}$, compared with $6.8 \mathrm{nM}$ for glibenclamide ${ }^{24}$. Thus it appears possible that the selectivity of glimeperide for the different types of sulfonylurea receptors in isolated cell patches differs from the in vivo situation. The reasons for these discrepancies, however, remain to be clarified.

As an induction of ischaemic precondition may also underlie the so called "warm up phenomenon", Ovunc investigated the effects of glibenclamide on this phenomenon in type 2 diabetic patients with chronic stable angina pectoris during two consecutive exercise stress tests. ${ }^{25}$ Under these conditions, glibenclamide abolished the improvement of the heart rate-pressure product during the second exercise test. ${ }^{25}$

However, clinical data are conflicting. Bogaty et al reported no effect of antidiabetic treatment with glibenclamide on the electrocardiographic shifts of the ST segment during repeated exercise tests in patients with type 2 diabetes ${ }^{26}$ while Correa

Table 2 Acute mortality after myocardial infarction in patients with type 2 diabetes mellitus treated with oral antidiabetic drugs including sulfonylureas and in normal subjects

\begin{tabular}{|c|c|c|c|c|c|c|c|c|c|}
\hline \multirow[b]{2}{*}{ Author } & \multicolumn{2}{|c|}{ Non-diabetic } & \multicolumn{2}{|c|}{$\begin{array}{l}\text { Type } 2 \text { diabetic patients } \\
\text { with sulfonylureas* }\end{array}$} & \multicolumn{2}{|c|}{$\begin{array}{l}\text { Type } 2 \text { diabetic patients without } \\
\text { sulfonylureas }\end{array}$} & \multirow[b]{2}{*}{ Insulin } & \multirow[b]{2}{*}{ Deceased (\%) } & \multirow[b]{2}{*}{ p Value } \\
\hline & No. & Deceased (\%) & No. & Deceased (\%) & No. & Diet/other OAD† & & & \\
\hline $\begin{array}{l}\text { Soler et } a l^{34} \\
\text { Rytter et } a l^{30} \\
\text { Garratt et } a l^{41} \\
\text { Klamann et } a l^{38} \\
\text { Halkin et } a l^{36}\end{array}$ & $\begin{array}{l}- \\
751 \\
- \\
357 \\
-\end{array}$ & $\begin{array}{l}- \\
152(20.2) \\
- \\
72(20.2) \\
-\end{array}$ & $\begin{array}{r}129 \\
54 \\
67 \\
76 \\
121\end{array}$ & $\begin{array}{r}59(45.7) \\
27(50.0) \\
7(11.0) \\
25(32.9) \\
19(15.7)\end{array}$ & $\begin{array}{r}156 \\
19 \\
118 \\
89 \\
124\end{array}$ & $\begin{array}{r}31 \\
8 \\
48 \\
42 \\
96\end{array}$ & $\begin{array}{r}125 \\
11 \\
70 \\
37 \\
28\end{array}$ & $\begin{array}{r}54(34.6) \\
5(26.3) \\
28(24.0) \\
29(32.6) \\
22(17.7)\end{array}$ & $\begin{array}{l}0.068 \\
0.023 \\
0.032 \\
1.0 \\
0.73\end{array}$ \\
\hline \multicolumn{10}{|c|}{$\begin{array}{l}\text { p Value: } \chi^{2} \text { test. } \\
\text { *Including chlorpropamide, tolbutamide, and glibenclamide. } \\
\text { tIncluding metformin and acarbose. } \\
\text { OAD, oral antidiabetic agents. }\end{array}$} \\
\hline
\end{tabular}


Table 3 Clinical situations where sulfonylurea treatment may be harmful and should therefore be avoided or discontinued

\begin{tabular}{|c|c|c|}
\hline Clinical situation & Explanation & Reference \\
\hline \multicolumn{3}{|l|}{$\begin{array}{l}\text { (1) Acute myocardial } \\
\text { infarction }\end{array}$} \\
\hline $\begin{array}{l}\text { (a) with acute } \\
\text { angioplasty }\end{array}$ & $\begin{array}{l}\text { Balloon inflation causes } \\
\text { a second period of ischaemia } \\
\text { following acute myocardial } \\
\text { infarction }\end{array}$ & 41 \\
\hline $\begin{array}{l}\text { (b) without emergency } \\
\text { coronary intervention }\end{array}$ & $\begin{array}{l}\text { Angioplasty can be necessary } \\
\text { at any time }\end{array}$ & $\begin{array}{l}\text { No } \\
\text { studies } \\
\text { available }\end{array}$ \\
\hline $\begin{array}{l}\text { (2) Unstable angina } \\
\text { pectoris }\end{array}$ & $\begin{array}{l}\text { Repeated or prolonged episodes } \\
\text { of myocardial ischaemia }\end{array}$ & 5 \\
\hline (3) Elective angioplasty & $\begin{array}{l}\text { Artificial induction of repeated or } \\
\text { prolonged intracoronary occlusion }\end{array}$ & 42 \\
\hline
\end{tabular}

and Schaefer found that exercise induced ST depression was not affected by glibenclamide pretreatment. ${ }^{27}$

All aspects considered, the available data indicate that the cardioprotective effect of ischaemic preconditioning can be abolished in vivo-in animals as well as in humans-by giving sulfonylurea compounds, particularly glibenclamide, in standard therapeutic doses.

\section{ENDPOINT TRIALS AND REGISTRIES}

To date, only two prospective and randomised studies have targeted the association between sulfonylurea treatment and cardiovascular mortality: the UGDP study and the UKPDS (UK prospective diabetes study). ${ }^{28}$ In the UGDP study, tolbutamide, a first generation sulfonylurea drug, was tested. ${ }^{2}$ The trial revealed an increased cardiovascular mortality in the sulfonylurea group. ${ }^{2}$ Glibenclamide, a second generation sulfonylurea with proved pharmacological affinity for SUR 2A receptors and sufficient potential to interfere with ischaemic preconditioning ${ }^{11}$ (table 1), was investigated in the UKPDS. No significant effect was found on either mortality or the incidence of cardiovascular events. ${ }^{28}$ Recently, an assessment of the Saskatchewan health databases over a follow up period of 5.1 years showed a significantly lower mortality in patients treated with metformin (13.8\%) compared with sulfonylurea monotherapy (24.7\%). ${ }^{29}$ However, while that result may have resulted from detrimental effects of sulfonylureas, it could also reflect a cardioprotective effect of metformin. The latter explanation is supported by a low mortality $(13.6 \%)$ in patients receiving metformin and sulfonylureas in combination. ${ }^{29}$ Also, the treatments were not randomised.

Because of the lack of clear evidence from prospective randomised trials, various smaller studies have targeted the interactions between sulfonylureas and ischaemic preconditioning. However, data are conflicting. Rytter and colleagues studied the acute mortality in 73 patients with type 2 diabetes who had developed acute myocardial infarction. ${ }^{30}$ They found that mortality was significantly higher in patients treated with oral antidiabetic agents $(50.0 \%)$ than in those treated with insulin $(9.1 \%)$ or diet alone $(25 \%)$. However, as tablet treatment was not further specified and included patients on treatment with tolbutamide, glibenclamide, metformin, or a combination of these agents, any detrimental effects such as increased mortality cannot be attributed to sulfonylureas alone with certainty. In addition, it is unclear whether the differences observed reflect detrimental effects of oral hypoglycaemic agents or beneficial effects of insulin treatment in the postinfarction period. The benefit arising from insulin treatment in patients with acute myocardial infarction has been demonstrated impressively in the DIGAMI (diabetes mellitus, insulin glucose infusion in acute myocardial infarction) study. In that study, 620 patients with type 2 diabetes who were admitted with a diagnosis acute myocardial infarction were randomised to either treatment with an insulin-glucose infusion followed by intensive subcutaneous insulin treatment in the postinfarction period, or to standard treatment. ${ }^{31}{ }^{32}$ The investigators found a $28 \%$ relative risk reduction for mortality during a 3.4 years follow up in the treatment group. ${ }^{31}$ However, these data might also be interpreted to show that withdrawal of sulfonylureas in the treatment group had contributed to a better outcome. ${ }^{33}$

Other follow up studies could not confirm an increased mortality after acute myocardial infarction in patients treated with sulfonylureas. ${ }^{34-36}$ In line with earlier data from Paasikivi, ${ }^{37}$ in our German cohort we did not find an association of sulfonylurea treatment before an acute myocardial infarct with either increased hospital mortality or infarct size..$^{38}$ Long term follow up for more than 3.5 years showed no detrimental effects of sulfonylureas either. ${ }^{39}$ Using the Health Care Financing Administration cooperative cardiovascular project database, 64171 patients with diabetes mellitus who had suffered a myocardial infarct were included in a recent analysis; it was shown that patients treated with sulfonylureas developed fewer complications and had lower in-hospital mortality than those treated with insulin. ${ }^{40}$ Again, treatment was not assigned by randomisation.

In conclusion, from the currently available clinical study data, there is no evidence that sulfonylureas increase the rate of cardiovascular events or mortality in patients with spontaneous coronary stenosis or occlusion.

\section{USE OF SULFONYLUREAS DURING REPEATED INTRACORONARY BALLOON INFLATION}

Although there is no evidence for detrimental effects of sulfonylureas in patients with type 2 diabetes under normal conditions, their use may worsen the prognosis of patients with type 2 diabetes mellitus in certain clinical situations. Such conditions arise if a period of myocardial hypoxia is followed by a second episode-that is, if ischaemic preconditioning is induced. A second ischaemic episode can be artificially produced by repetitive inflation of an intracoronary balloon catheter, ${ }^{5}$ but it can also occur spontaneously. In case of emergency angioplasty after acute myocardial infarction, balloon inflation in the coronary artery irritates the myocardium a second time. Accordingly, Garratt et al reported an increased in-hospital mortality in type 2 diabetic patients taking sulfonylureas following immediate balloon angioplasty for acute myocardial infarction. ${ }^{41}$ Moreover, O'Keffe et al analysed the long term survival after elective coronary angioplasty and coronary bypass surgery in 1938 patients with type 2 diabetes mellitus. They found that the use of sulfonylureas was associated with a worse outcome after angioplasty, but not after coronary bypass surgery. ${ }^{42}$

\section{SUMMARY AND CONCLUSIONS}

Despite the fact that clear evidence for an impairment of ischaemic preconditioning by sulfonylureas can be obtained from various animal studies and from indirect experimental studies in humans, there is still no evidence for a detrimental effect on cardiovascular mortality in patients with type 2 diabetes mellitus. Our discussion of any potentially detrimental effects of the sulfonylureas is based on the increased cardiovascular mortality observed in the UGDP study. ${ }^{2}$ However, as the affinity of tolbutamide, the sulfonylurea used in the UGDP study, for cardiac SUR 2A receptors is relatively low, ${ }^{11}$ an interference with ischaemic preconditioning seems an unlikely explanation for the results found in that study (table 1). In contrast, glibenclamide-a 
sulfonylurea with a high affinity for cardiac SUR 2A receptors ${ }^{11}$ and with well documented effects on ischaemic preconditioning under experimental conditions ${ }^{18}$ - failed to alter cardiovascular mortality in the UKPDS. ${ }^{28}$ Thus the UGDP results are more likely to reflect methodological deficiencies of the study design than any direct detrimental effects exerted by sulfonylureas per se. ${ }^{43}$

Taking smaller follow up studies into consideration, the use of sulfonylureas does not appear to worsen the prognosis of patients with type 2 diabetes after acute myocardial infarction in general terms (table 2). In contrast, sulfonylurea treatment may increase mortality in patients with type 2 diabetes when subjected to elective or emergency balloon angioplasty. ${ }^{41}{ }^{42}$ Although experimental data highlight compound specific differences between the various sulfonylureas $^{17}$ (table 1), this has not yet been evaluated in clinical trials. Further clinical trials will be necessary.

In conclusion, from the present data it seems worth reconsidering the use of sulfonylureas in cases of elective or emergency angioplasty (table 3 ). As the DIGAMI study provided striking evidence for the benefit of tight glucose control with an intensive insulin treatment regimen during the peri-infarction period, ${ }^{31}$ this method of treatment appears to be a suitable alternative.

\section{Authors' affiliations}

J J Meier, Diabeteszentrum Bad Lauterberg, Bad Lauterberg im Harz, Germany

B Gallwitz, W E Schmidt, A Mügge, M A Nauck, Departments of Medicine I and II, St Josef Hospital, Ruhr-University Bochum, Bochum, Germany

\section{REFERENCES}

1 Gerich J. Oral hypoglycemic agents. N Engl J Med 1989;321:1231-45.

2 Meinert CL, Knatterud GL, Prout TE, et al. A study of the effects of hypoglycemic agents on vascular complications in patients with adult-onset diabetes. Diabetes 1970;19:789-830.

3 Gross G, Auchampach JA. Blockade of ATP-sensitive potassium channels prevents myocardial preconditioning in dogs. Circ Res 1992;70:223-33.

4 Toombs CF, Moore TL, Shebuski RJ. Limitation of infarct size in the rabbit by ischaemic preconditioning is reversible with glibenclamide. Cardivasc Res 1993:27:617-22.

5 Tomai F, Crea F, Gaspardone A, et al. Ischemic preconditioning during coronary angioplasty is prevented by glibenclamide, a selective ATP-sensitive $\mathrm{K}^{+}$channel blocker. Circulation 1994;90:700-5.

6 Smits $\mathbf{P}$, Thien T. Cardiovascular effects of sulphonylurea derivatives. Implications for the treatment of NIDDM? Diabetologia 1995;38:116-21.

7 Groop L. Sulfonylureas in NIDDM. Diabetes Care 1992;15:737-54.

8 Engler RL, Yellon DM. Sulfonylurea $\mathrm{K}_{\text {ATP }}$ blockade in type 2 diabetes and preconditioning in cardiovascular disease: time for reconsideration. Circulation 1996:94:2297-301.

9 Brady PA, Terzic A. The sulfonylurea controversy: more questions from the heart. J Am Coll Cardiol 1998;31:950-6.

10 Chutkow WA, Simon MC, Le Beau MM, et al. Cloning, tissue expression, and chromosomal localisation of SUR2, the putative drug-binding subunit of cardiac, skeletal muscle, and vascular $\mathrm{K}_{\text {ATP }}$ channels. Diabetes 1996;45: 1439-45.

11 Gribble FM, Tucker SJ, Seino S, et al. Tissue specificity of sulfonylureas: studies on cloned cardiac and beta-cell K KTP channels. Diabetes 1998:47:1412-18.

12 Ashfield R, Gribble FM, Ashcroft SJH, et al. Identification of the high-affinity tolbutamide site on the SUR1 subunit of the $\mathrm{K}_{\text {ATP }}$ channel. Diabetes 1999;48:1-7.

13 Gribble FM, Ashcroft FM. Differential sensitivity of beta-cell and extrapancreatic K ATP channels to gliclazide. Diabetologia 1999:42:845-8.

14 Song DK, Ashcroft FM. Glimepiride block of cloned beta-cell, cardiac and smooth muscle K(ATP) channels. Br J Pharmacol 2001;133:193-9.

15 Dabrowski M, Wahl P, Holmes WE, et al. Effect of repaglinide on cloned beta cell, cardiac and smooth muscle types of ATP-sensitive potassium channels. Diabetologia 2001;44:747-56.

16 Hu S, Dunning BE. Tissue selectivity of antidiabetic agent nateglinide: study on cardiovascular and beta-cell K ATP channels. J Pharmacol Exp Ther 1999;291:1372-9.
17 Mocanu MM, Maddock HL, Baxter GF, et al. Glimepiride, a nove sulfonylurea, does not abolish myocardial protection afforded by either ischemic preconditioning or diazoxide. Circulation 2001;103:3111-16.

18 Cleveland JC, Meldrum DR, Cain BS, et al. Oral sulfonylurea hypoglycemic agents prevent ischemic preconditioning in human myocardium: two paradoxes revisited. Circulation 1997;96:29-32.

19 Scognamiglio R, Avogaro A, Vigili de Kreutzenberg S, et al. Effects of treatment with sulfonylurea drugs or insulin on ischemia-induced myocardial dysfunction in type 2 diabetes. Diabetes 2002;51:808-12.

20 Lee TM, Su SF, Chou TF, et al. Loss of preconditioning by attenuated activation of myocardial ATP-sensitive potassium channels in elderly patients undergoing coronary angioplasty. Circulation 2002;105:334-40.

21 Klepzig H, Kober G, Matter C, et al. Sulfonylureas and ischaemic preconditioning; a double-blind, placebo-controlled evaluation of glimepiride and glibenclamide. Eur Heart J 1999;20:439-46.

22 Lee TM, Chou TF. Impairment of myocardial protection in type 2 diabetic patients. J Clin Endocrinol Metab 2003;88:531-7.

23 Li RA, Leppo M, Miki T, et al. Molecular basis of electrocardiographic STsegment elevation. Circ Res 2000;87:837-9.

24 Geisen K, Vegh A, Krause E, et al. Cardiovascular effects of conventional sulfonylureas and glimepiride. Horm Metab Res 1996;28:496-507.

25 Ovunc K. Effects of glimepiride, a K(ATP) channel blocker, on warm-up phenomenon in type II diabetic patients with chronic stable angina pectoris. Clin Cardiol 2000;23:535-9.

26 Bogaty P, Kingma JG, Robitaille NM, et al. Attenuation of myocardial ischemia with repeated exercise in subjects with chronic stable angina: relation to myocardial contractility, intensity of exercise and the adenosine triphosphate-sensitive potassium channel. J Am Coll Cardiol 1998;32:1665-71.

27 Correa SD, Schaefer S. Blockade of K(ATP) channels with glibenclamide does not abolish preconditioning during demand ischemia. Am J Cardiol 1997:79:75-8.

28 UK Prospective Diabetes Study (UKPDS) Group. Intensive blood-glucose control with sulphonylureas or insulin compared with conventional treatment and risk of complications in patients with type 2 diabetes. Lancet 1998;352:837-53

29 Johnson JA, Majumdar SR, Simpson SH, et al. Decreased mortality associated with the use of metformin compared with sulfonylurea monotherapy in type 2 diabetes. Diabetes Care 2002;25:2244-8.

30 Rytter L, Troelsen S, Beck-Nielsen H. Prevalence and mortality of acute myocardial infarction in patients with diabetes. Diabetes Care 1985;8:230-4.

31 Malmberg K. Prospective randomised study of intensive treatment on long term survival after myocardial infarction in patients with diabetes mellitus: DIGAMI (diabetes mellitus, insulin glucose infusion in acute myocardial infarction) study group. BMJ 1997;314:1512-15.

32 Malmberg K, Norhammer A, Wedel H, et al. Glycometabolic state at admission: important risk marker of mortality in conventionally treated patients with diabetes mellitus and acute myocardial infarction: long-term results from the diabetes and insulin-glucose infusion in acute myocardial infarction (DIGAMI) study. Circulation 1999;99:2626-32.

33 Mühlhauser I, Sawicki PT, Berger M. Possible risk of sulfonylureas in the treatment of non-insulin-dependent diabetes mellitus and coronary artery disease. Diabetologia 1997;40:1492-6.

34 Soler NG, Pentecost BL, Bennet MA, et al. Coronary care for myocardial infarction in diabetics. Lancet 1974; i:475-7.

35 Ulvenstam G, Aberg A, Bergstrand R, et al. Long-term prognosis after myocardial infarction in men with diabetes. Diabetes 1985;34:787-92.

36 Halkin A, Roth A, Jonas $M$, et al. Sulfonylureas are not associated with increased mortality in diabetics treated with thrombolysis for acute myocardial infarction. J Thromb Thrombolysis 2001;12:177-84.

37 Paasikivi J. Long-term tolbutamide treatment after myocardial infarction. A clinical and biochemical study of 178 patients without overt diabetes. Acto Med Scand Suppl 1970;507:1-82.

38 Klamann A, Sarfert P, Schulte G, et al. Myocardial infarction in diabetic versus non-diabetic subjects. Relation of survival and infarct size to therapy with sulfonylureas (glibenclamide). Eur Heart J 2000;21:220-9.

39 Meier JJ, Deifuss S, Klamann A, et al. Influence of an antidiabetic treatment with sulfonylurea drugs on long-term survival after myocardial infarction in type 2 diabetic patients [abstract]. Diabetologia 2001;44(suppl 1):A69.

40 Jollis JJ, Simpson RJ, Cascio WE, et al. Relation between sulfonylurea therapy, complications, and outcome for elderly patients with acute myocardial infarction. Am Heart J 1999; 138:376-80.

41 Garratt KN, Brady PA, Hassinger NL, et al. Sulfonylurea drugs increase early mortality in patients with diabetes mellitus after direct angioplasty for acute myocardial infarction. J Am Coll Cardiol 1999;33:119-24.

42 O'Keefe JH, Blackstone EH, Sergeant $P$, et al. The optimal mode of coronary revascularisation for diabetics. A risk-adjusted long-term study comparing coronary angioplasty and coronary bypass surgery. Eur Heart $J$ 1998;19:1601-3.

43 Seltzer HA. A summary of criticisms of the findings and conclusions of the University Group Diabetes Program (UGDP). Diabetes 1972;21:4-11. 